\title{
CORRECTION
}

View Article Online

View Journal I View Issue

Check for updates

Cite this: J. Mater. Chem. A, 2021, 9 , 11456

DOI: $10.1039 / \mathrm{d} 1 \mathrm{ta90089g}$

rsc.li/materials-a

\section{Correction: Hollow Au nanorattles for boosting the performance of organic photovoltaics}

\author{
Zhi Yong Bao, ${ }^{\text {ab }}$ Shenghua Liu, ${ }^{\mathrm{b}}$ Yidong Hou, ${ }^{\mathrm{d}}$ Aixue Shang, ${ }^{\mathrm{b}}$ Feng Yan, ${ }^{\text {b }}$ \\ Yucheng $\mathrm{Wu}^{a}{ }^{a}$ Dangyuan Lei ${ }^{\star \mathrm{c}}$ and Jiyan Dai ${ }^{\star \mathrm{b}}$
}

Correction for 'Hollow Au nanorattles for boosting the performance of organic photovoltaics' by Zhi Yong Bao et al., J. Mater. Chem. A, 2019, 7, 26797-26803, DOI: 10.1039/C9TA07974B.

The authors regret that a project funder was omitted from the Acknowledgements section in the published article. The corrected Acknowledgements section should read as follows.

This work was financially supported by the National Natural Science Foundation of China (Grant No. 51802066), the Fundamental Research Funds for the Central Universities of China (Grant No. JZ2019YYPY0023), the Research Grants Council (RGC) of Hong Kong, China (project number: C4030-14G), and the National College Students Innovation and Entrepreneurship Training Program (201910359095). Prof. Y. Wu acknowledges the financial support from the 111 Project "New Materials and Technology for Clean Energy" (B18018). We thank Dr Y. Zhu for performing parts of TEM measurement.

The Royal Society of Chemistry apologises for these errors and any consequent inconvenience to authors and readers. 